\title{
O DIREITO ENTRE O POSITIVISMO E O PÓS-POSITIVISMO JURÍDICO: POR UMA TEORIA IMPURA DO DIREITO
}

\author{
ALOÍSIO ALENCAR BOLWERK \\ GUSTAVO PASCHOAL T. CASTRO OLIVEIRA
}




\title{
O DIREITO ENTRE O POSITIVISMO E O PÓS- POSITIVISMO JURÍDICO: POR UMA TEORIA IMPURA DO DIREITO
}

\author{
Aloísio Alencar Bolwerk ${ }^{1}$ \\ Gustavo Paschoal Teixeira de Castro Oliveira²
}

\section{RESUMO}

O estudo procura apontar crítica ao método positivista de interpretação do direito e apresentar a abordagem metodológica pós-positivista que procura ensejar adequação entre o fato jurídico e a dinâmica social. Tem por objetivo verificar análise aberta do Direito ante os resultados operacionais que se pretende alcançar. Para tanto, valerse-á da apreciação qualitativa, analisando pontos centrais sobre o pós-positivismo, bem como as metodologias e técnicas interpretativas empregadas. O pensamento neoconstitucional também é objeto de exame, assim como sua percepção hermenêutica de recepção e aplicação do Direito, considerando-se o princípio constitucional da dignidade da pessoa humana enquanto diretriz norteadora dessa vertente jurídica. Por fim, buscar-se-á evidenciar a necessidade de convergência de entendimentos em relação a uma perspectiva que acarreta numa constante (re)alimentação alopoiética do conhecimento jurídico, possibilitando contribuição de inovação sobre o tema.

Palavras-chave: Direito. Positivismo. Pós-positivismo. Metodologia. Interpretação. Aplicação.

1 Doutorando em Direito Privado pela Pontifícia Universidade Católica de Minas Gerais. Professor de Direito Constitucional da Universidade Federal do Tocantins, de Teoria do Direito do CEULP/ULBRA. Coordenador do Curso de Direito da Faculdade Ciências Jurídicas de Paraíso do Tocantins. Advogado.

2 Doutorando em Direito das Relações Internacionais pelo Centro Universitário de Brasília. Coordenador do Curso de Direito do CEULP/ULBRA. Professor de Direito Internacional da Universidade Federal do Tocantins. Advogado. 


\section{RESUMEN}

El estudio pretende dar a conocer la crítica del método positivista de la interpretación de la Ley y tiene el enfoque metodológico postpositivista que busca dar suficiencia ascenso de la evolución jurídica y la dinámica social. Tiene como objetivo verificar el análisis abierto de la ley en contra de los resultados de las operaciones que se deben alcanzar. Así que, vamos a hacer uso de la evaluación cualitativa, analizando núcleo en puntos post- positivismo, así como las metodologías y técnicas interpretativas empleadas. El pensamiento neo-constitucional también está sujeto a examen, así como su percepción hermenéutica de la recepción y aplicación de la Ley, teniendo en cuenta el principio constitucional de la dignidad humana como una guia legal orientar este aspecto. Por último, vamos a tratar de poner de relieve la necesidad de una convergencia de acuerdos en relación con una perspectiva que implica una constante (re)alimentación abierta del conocimiento jurídico, lo que permite contribuir a innovar en el tema.

Palabras-clave: Derecho. Positivismo. Post-positivismo. Metodología. Interpretación. Solicitud.

\section{INTRODUÇÃO}

As relações sociais são marcadas pela mutabilidade e capacidade de transição que estão suscetíveis ao tempo e ao espaço. O Direito, apresentado enquanto sistema e instrumento normativo, já não consegue acompanhar e se adequar ao ritmo do embalo assistemático da sociedade. Mas é nesse enredo de certa "imperfeição" que a "Ciência Jurídica" aporta-se em métodos e critérios interpretativos para refletir o "pensar do fenômeno da dinâmica social"’3.

3 Importante consignar desde já o enfoque atribuído ao Direito, enquanto Ciência, portanto, dotado de método sistematizado e natureza tecnicista e mecânica, e também como obra da atividade social, da ação comunicativa da realidade fenomênica, esta sim, imperfeita, 
Assim é que o Direito, em sua vertente atrelada ao modelo estruturante de compilação legislativa, tendo como símbolo maior dessa representatividade a codificação das leis, passou a receber interpretações novas que romperam com a moldura interpretativa que outrora fora implantada e segmentada na Ordem Jurídica pátria. Tal mudança de paradigma teve início na Europa por meio da corrente pós-positivista, ganhando força e amplitude no Direito brasileiro a partir da promulgação da Constituição de 1988. Nesse passo, a tendência jurídica - atualmente representada não apenas pela ordem normativa positivada, mas também por critérios hermenêuticos de interpretação do Direito e pelo ativismo judicial - ganha espaço para estabelecer novos paradigmas de compreensão e adequabilidade do Direito, que já não pode ser mais analisado como um conjunto normativo estruturante de regras, tampouco como um complexo sistema de comandos normativos positivados e ordenados dentro de Códigos que de per si tinham soberania normativa sobre qualquer outro tipo de fonte ou mesmo método jurídico de interpretação alopoiética.

Nessa senda, este artigo defende a ideia de interpretação e aplicação do Direito alinhado à corrente pós-positivista, cuja consequência termina por abrir novos caminhos (métodos) para uma interpretação que encontre convergência com as reais expectativas desencadeadas pelos fatos sociais. 


\section{DO POSITIVISMO AO PÓS-POSITIVISMO: A QUESTÃO DO MÉTODO JURÍDICO}

O Movimento Positivista foi fruto da necessidade do contexto social apresentado no período Moderno denominado "sociedade". Trata-se de modelo que modificou conceitos e afetou diversas estruturas, a exemplo do Direito (Positivismo Jurídico), fazendo surgir a concepção de ordenamento jurídico enquanto criação da vontade humana.

É no ritmo desse passo epistemológico que o Positivismo Jurídico passa a promover a leitura do Direito, encontrando na lei o método (mecanismo) pelo qual pretendeu converter o conhecimento jurídico em "Ciência". Assim, construtos a respeito do Direito foram moldados, como o da neutralidade, sistematização e do reducionismo. Contudo, o modelo Positivista adotado entra em crise, mostrando-se cada vez mais ineficaz e inadequado. Um novo pensamento, chamado de pós-positivismo, passa a ganhar espaço ao conhecimento jurídico (GALUPPO, on line, 2014).

Certo é que há uma crise que afeta e gera angústia em relação ao Direito; os construtos jurídicos já não são mais capazes de promover ajuste e adequação social (e talvez isso nunca tenha acontecido, fruto apenas de um ideal construtivista fictício de realização material do direito). A técnica das ciências naturais aplicadas ao Direito ainda é uma realidade, e que não se julgue enquanto incorreta, mas como meio mecânico de amoldar e conformar a aplicação da norma à sociedade. Certo é também 
que a estrutura social é dinâmica, plural e mutável, e a técnica cientificista adotada não atinge os anseios sociais. É preciso ter em mente que o Direito trabalha com o fator social (humano). A conduta humana, por sua natureza, não está constrita ao completo, acabado, preestabelecido, mas ao imperfeito, ao não cientificado. A racionalidade que o Positivismo Jurídico imprime ao Direito é contraditória com essa natureza diversificada, não previsível de existência humana.

Assim é que a proposta pós-positivista acarreta na quebra de pré-conceitos, a exemplo do rigorismo normativista, da tecnicidade e mecanicidade da aplicação do Direito, a da regra geral de subsunção do fato social à norma jurídica abstrata. Ao contrário dessa visão, o homem é a matéria-prima da obra comunicativa social. É dessa atividade, portanto, que deve sair o substrato do conhecimento jurídico. Dessa perspectiva de dinâmica, diversidade, autonomia e liberdade é que se deve refletir a adequação da norma jurídica ${ }^{4}$.

Essa adequabilidade proposta pela interpretação póspositivista humaniza a aplicação do direito. Assim, o presente trabalho preocupa-se em rebater o pensamento sistemáticoaxiomático atribuído ao Direito, no qual

qualquer processo de aplicação do direito é concebido como existente prévia e independentemente da realidade a que se refere. As normas

4 Nesse ponto percebe-se a metodologia dedutiva empregada pelo positivismo jurídico, que formula situação geral para ser aplicada a um caso particular. Diferentemente do método da indução proposto pelo pós-positivismo, que corresponde ao raciocínio que, após considerar um número suficiente de casos particulares, conclui uma verdade geral. 
jurídicas a serem aplicadas são entendidas em uma hierarquia auto-existente e auto-evidente, independendo da situação concreta. (...) Os conteúdos do problema que não se conciliam com o ponto de vista são rejeitados. O pensamento sistemático preocupa-se em aferrar-se a verdades preestabelecidas. Elegeu como modelo a estrutura dedutiva da matemática. Proporcionar um sistema completo de demonstrações por meio de conceitos básicos irrefutáveis. (GALUPPO, on line, 2014).

Logo, a pertinência da humanização do Direito deve entrar em cena no sentido de que a matéria com a qual se envolve (trabalha) é o fator humano; o homem envolvido no complexo enredo de seu existencialismo, e o produto a ser ofertado dessa relação deve se coadunar com suas expectativas. Nesse sentido, Galuppo:

Ao contrário do pensamento sistemático-axiomático, a argumentação jurídica, pela qual aplicamos o direito ao caso concreto, não se faz partindo do sistema, ou das normas, em direção ao caso concreto, mas do caso concreto em direção às normas adequadas (correção normativa) àquele caso. Essa posição caracteriza o pensamento problemático, que não exclui de seu método a ideia de sistema, mas que o concebe como fruto da reconstrução dialógica retrospectiva do ordenamento pelo intérprete e não como fruto de uma construção monológica prospectiva realizada pelo legislador (grifo nosso). (on line 2014).

Nota-se que a leitura pós-positivista valora o caso 
particular. Contudo, não pretende estabelecer uma técnica específica (método) a se seguir, pois isso acarretaria um enraizamento metodológico de aplicação do Direito. Do mesmo modo, descaracteriza o construto de que o Direito é estatuto científico porque sua base está calcada em fenomenologia social, ou seja, no que concerne ao existencialismo humano.

No que tange à metodologia a ser empregada, esta deve se constituir a partir da apreciação do fato. Noutros termos "não há um método preestabelecido que sirva ao direito para a solução dos conflitos humanos, mas cada caso cria seu próprio método. Ou seja, os métodos jurídicos devem ser dialéticos, particularizados, erguidos e sustentados" (GONTIJO, 2011, p. $66)^{5}$. Complementa o autor, estabelecendo que

A teoria antipositivista apresentada não pretende chegar ao limite de um, por assim dizer, desconstrutivismo jurídico. Procura-se tão-somente, flexibilizar a rigidez dos métodos de conhecimento e a aplicação do direito, a fim de trazer maior aproximação deste com as pelejas humanas. Busca-se, pois, particularizar a aplicação dos métodos jurídicos e mantê-los atentos às possíveis exigências peculiares de cada caso (grifo nosso). (p. 129) ${ }^{6}$.

É importante trazer à baila, ainda que de maneira incipiente, a discussão sobre a necessidade de se atribuir ao Direito

$5 \quad$ O autor apresenta proposta de método jurídico aberto, destacando dentre eles o pensamento dialético, p. 111.

6 Para atingir esse fim multifacetado interpretativo, Gontijo utiliza-se da Hermenêutica e seu denso campo de possibilidades, p. 129. 
natureza cientificista, como vem sendo pregado (dogmatizado) pelo positivismo jurídico. Não se pretende aqui afirmar a ideia de que o Direito não assume o "status" científico, mas sim de arrazoar sobre o modo como vem sendo empreendida essa qualificação por meio da metodologia positivista, ao equalizálo às ciências exatas e ao unilateralizá-lo ao método dedutivo (subsunção) de análise.

O produto humano não pode estar adstrito a uma única metodologia, pois não se está lidando com algo consistente, ou com alguma verdade humana perfeita, absoluta e universalmente aplicada indistintamente. A inconsistência da natureza do homem, de suas ações, vontades e aspirações ${ }^{7}$ ultrapassa o dogma de que a lei é a fonte de resposta e o que está fora de seu raio normativo não pode ser resguardado porque não é jurídico ou permitido. O conhecimento que leva ao conteúdo jurídico deve ser aberto para novas propostas de se refletir o Direito (pluralidade de metodologias, sem necessidade de se fixar qual deve ser empregada). Nesse sentido, ganha ares de Ciência, à medida que sua reflexão ascende para novos caminhos e percepções de análises ${ }^{8}$.

Ocorre que a unicidade metodológica do positivismo jurídico intenta condicionar a atividade humana, estandardizando

$7 \quad$ Essa inconsistência ganha projeção na dinâmica das relações sociais quando se lida com a autonomia da vontade do homem. Autonomia esta concernente ao seu grau de consciência, portanto, quanto à sua percepção na condição de sujeito cognoscente.

8 "Diríamos que o Direito é como o Rei Midas: se na lenda grega esse monarca convertia em ouro tudo aquilo em que tocava, aniquilando-se na sua própria riqueza, o Direito, não por castigo, mas por destinação ética, converte em jurídico tudo aquilo que toca, para dar-lhe condições de realizabilidade garantida, em harmonia com os demais valores sociais". (REALE, 2009 , p. 22). 
comportamentos segundo parâmetros de legalidade (im)posta pela vontade do legislador. Sobre o assunto, Grau assevera que

(...) como sujeito e objeto encontram-se em relação de funcionalidade reciproca e a matéria isto é, o conjunto das relações do homem social com a natureza - é uma variável independente da consciência humana, as relações sociais são objetivas, estando fora do sujeito que pode pensá-las; mas a atividade sensível e prática (consciente) dos homens modifica as circunstâncias e o estado dado das relações entre a humanidade e a natureza. A atividade humana, pois, modifica as relações sociais. Assim, o direito pressuposto brota da (na) sociedade, à margem da vontade individual dos homens, mas a prática jurídica modifica as condições que o geram. (...) $\mathrm{O} d i$ reito pressuposto condiciona a elaboração do direito posto, mas este modifica o direito pressuposto. O direito que o legislador não pode criar arbitrariamente - insisto - é o direito positivo. $\mathrm{O}$ direito pressuposto condiciona o direito posto (positivo). Mas o direito posto transforma sua (dele) própria base (grifos do autor). (1996, p. 44).

Como se nota, o fator humano é imprescindível para a construção do conhecimento jurídico, conteúdo este que não precisa ser estático, posto estar-se a lidar com direitos inerentes ao homem (direitos humanos ${ }^{9}$ ). A teoria subjetiva cede espaço,

9 Faz-se referência, neste momento, à importância da análise de "verdades autoevidentes", destacando o conteúdo das Declarações da Independência (1776), dos Direitos do Homem e do Cidadão (1789), e, por fim, Universal dos Direitos Humanos (1948), sendo que esta "cristalizou 150 anos de luta pelos direitos". (HUNT, p. 207, 2009). 
portanto, à teoria objetiva. A mens legis ganha força a partir do momento em que se constata a necessidade de se pensar e refletir o Direito, com intuito de concretização de justiça.

Contemporaneamente, a força irradiadora desses direitos é vertente, e passa a ser fonte de interpretação do direito interno dos Estados Soberanos. Esse acontecimento teve início no Brasil com o advento da Constituição Federal de 1988, marcando uma nova tendência denominada, por alguns autores, de neoconstitucionalismo. Essa tendência está principalmente arrimada no princípio da dignidade da pessoa humana, expresso no inciso III, do artigo $1^{\circ}$ da Carta Constitucional enquanto fundamento da República Federativa do Brasil ${ }^{10}$.

\section{A CONTRIBUIÇÃO DO DIREITO CONSTITUCIONAL}

A mudança de paradigma interpretativo do Direito teve início na Europa por meio da corrente pós-positivista e também do fenômeno do neoconstitucionalismo ${ }^{11}$, ganhando força e amplitude no Direito Brasileiro a partir da promulgação da Constituição Federal de 1988.

10 Importante consignar que para alguns autores, a exemplo de Rizzatto Nunes, a dignidade da pessoa humana é um "supraprincípio", que constitui valor supremo enquanto resposta lapidada pela razão jurídica, cuja conquista fora fruto da realidade histórica que marcou a experiência humana (pp. 46-48, 2002).

11 Não se sabe precisar o termo inicial do neoconstitucionalismo. Contudo, sabe-se que passou a ter pertinência social e relevância jurídica após a $2^{\text {a }}$ Guerra Mundial. Para alguns autores é insegura ou inadequada a mencionada expressão, pois dá a ideia de criação de um novo direito constitucional. Nesse sentido BULOS, 2010, p. 79 e em sentido contrário BARROSO, 2010, p. 267. 
Em relação ao neoconstitucionalismo, este é fruto da filosofiapós-positivistadeimplantaçãodeumanovaHermenêutica que intensificou a força normativa da Constituição, decodificando o Direito, "cujos ramos saíram da órbita infraconstitucional, passando para o campo constitucional" (BULOS, 2010, p. 80). Porém, pensar num novo direito constitucional (neo) não significa necessariamente criar novos princípios e regras, mas sim abordar a Constituição num plano humano e de mutação constitucional (e não de reforma constitucional) a se adequar à realidade social. É preciso entender que a "regulação que no presente é requisitada ao Direito assume um caráter finalístico, e um sentido prospectivo" (GUERRA FILHO, 1997, p. 17).

Constata-se, portanto, da preocupação da ciência jurídica para com o anseio social. O enredo dos direitos humanos abraçou o conteúdo jurídico, no que toca sua (re)interpretação, surtindo efeitos principalmente no direito privado erigido sob a nova perspectiva paradigmática da repersonalização, que em verdade contempla essa tendência humanística de ponderar o Direito. Barroso defende tal visão sistêmica ao discorrer que

O direito privado, especialmente o direito civil, atravessou os tempos sob o signo da livre iniciativa e da autonomia da vontade. As doutrinas individualista e voluntarista, consagradas pelo Código de Napoleão (1804) e incorporadas pelas codificações do século XIX, repercutiram sobre o Código Civil de 1916. A liberdade de contratar e o direito de propriedade fundiam-se para formar o centro de gravidade do sistema privado (...). A progressiva superação do liberalismo 
puro pelo intervencionismo estatal trouxe para o domínio do direito privado diversos princípios limitadores da liberdade individual e do primado da vontade, denominados princípios de ordem pública (...). A proliferação de normas cogentes, indisponíveis pelos contratantes, assinala a denominada publicização do direito privado (grifos do autor). (2010, p. 59).

A publicização acentuada pelo autor reflete a mudança de paradigma que denotou na doutrina pós-positivista da constitucionalização do Direito Civil. Um Direito sem perder de vista o foco singular e particularizado, mas atinente ao juízo coletivo de análise.

A Constituição é cidadã, prega o estado do bem-estar social e a favor do homem e de sua dignidade. Da análise de seu substrato normativo faz-se perceber um conhecimento jurídico erigido em base principiológica que - a partir do ato interpretativo - permite mutabilizar suas disposições; também está calcada na humanização das relações sociais a partir de conteúdos axiológicos de cooperação, igualdade substancial, prevalência dos direitos humanos ${ }^{12}$ e também pela eficácia e efetiva aplicação dos direitos às situações concretas. O Direito

12 Em obra intitulada "A filosofia dos direitos do homem", busca Haarcher, por meio de conhecimentos sobre as Constituições e Declarações dos povos, discorrer sobre a necessidade da humanidade em refletir sobre os direitos considerados como "humanos", levando-se a urgente necessidade de sua efetiva implantação e cumprimento, não se deixando induzir pela "recuperação politiqueira" ou pela "ingenuidade bem intencionada das grandes proclamações humanistas, ineficazes por excesso de generalidade e inflação de grandes sentimentos”. Entende-se, por estas palavras, que Haarcher busca enfatizar a necessidade de que todos os que encampam a essência dos direitos do homem necessitam de uma visão realista e concreta dos fatos geradores de desrespeito ao cumprimento de tais direitos, no sentido de menos comoção e mais ação. (p. 12, 1993) 
não ficou alheio a esse espírito humanístico e passou a suportar a força irradiadora constitucional de natureza pós-positivista, e a pari passu o conhecimento jurídico ganha contornos interpretativos que flexibilizam e humanizam sua aplicação às relações sociais.

Nesse passo epistemológico é que outros princípios, implícitos ao conhecimento constitucional, como o da socialidade, eticidade e o da operabilidade "contaminaram" (ou tendem a essa "contaminação") em virtude da força irradiadora da Carta Constitucional, cuja interpretação se mostra cada vez mais aberta e tendente à percepção do homem e de seu espaço realístico fruto da ação comunicativa humana. Como exemplo dessa fenomenologia jurídica, cita-se a figura normativa do Código Civil, Lei $\mathrm{n}^{\mathrm{o}} 10.406$, de janeiro de 2002, que passou a incorporar em seu tecido textual capítulo reservado aos direitos da personalidade (arts. 11 a 21); tratou da figura do dano moral e da possibilidade de ofensa a essa garantia no artigo 186, ao prescrever que comete ato ilícito aquele que "por ação ou omissão voluntária, negligência ou imprudência, violar direito e causar dano a outrem, ainda que exclusivamente moral" (grifo nosso); estabeleceu nos arts. 421e 2.035 e respectivo parágrafo único a função social do contrato e da propriedade; inseriu título sobre a união estável (arts. 1.723 a 1.727), abordando aspectos pessoais e patrimoniais e deixando a cargo do direito das sucessões o efeito patrimonial sucessório (artigo 1.790); consolidou o ideal de igualdade das relações de parentesco reproduzida no artigo 1.596, ao dispor que "os filhos, havidos ou não da relação 
de casamento, ou por adoção, terão os mesmos direitos e qualificações, proibidas quaisquer designações discriminatórias relativas à filiação"; e na sucessão testamentária (artigo 1.799, inciso I) inovou ao disciplinar que podem também ser chamados a suceder os filhos, ainda não concebidos, de pessoas indicadas pelo testador (prole eventual).

Noutros termos, antes o fato social era apreciado e valorado na sociedade em seus contornos materiais e econômicos e surtia efeitos de ordem e amparo patrimonial na esfera jurídica do Direito. Agora, tem-se o fato social que, embora eivado de axiologia patrimonial, primeiramente deve ser valorado sob a perspectiva de aplicação humana e personalizada do Direito, fruto dessa tendência jurídico-interpretativa neoconstitucional que se sustenta, sobretudo, no ideal de humanização das relações sociais $^{13}$.

\subsection{O pós-positivismo e o neoconstitucionalismo: uma resposta ao direito positivo}

Apesar dessa vertente interpretativa do Direito que, em tese, tem inclinação para lhe atribuir maior efetividade social, é de se notar duas formas de se analisá-lo. A primeira parte da perspectiva positivista, ainda preponderante tanto na academia como no meio jurídico em geral, e que concebe o Direito de modo codificado, de conteúdo jurídico sistematizado, hermético

13 Observa-se que nessa passagem a incidência da Teoria Tridimensional do Direito. Para maiores considerações vide REALE, 2009, p. 64. 
e completo a regular os fatos sociais (forma pura de análise do Direito observada por Hans Kelsen). Já numa segunda análise, pós-positivista, parte-se do pressuposto de um Direito aberto, alopoiético; e que sob um olhar um tanto quanto intuitivo e de percepção existencialista compreende as relações privadas tendo como objeto a experiência dos casos concretos ${ }^{14}$.

A problemática metodológica de interpretação e aplicação do Direito está no paradoxo epistemológico situado na questão da gênese humana entrelaçada ao conteúdo jurídico entre o método positivista de construção e emprego do Direito e a interpretação pós-positivista, que vislumbra conteúdos e produtos jurídicos alinhados a resultados de percepção da dinâmica social, posto os fatos sociais desembocarem no Judiciário e este já não pode mais se manter atrelado à antiga postura dogmática de interpretar literalmente as disposições jurídicas, pois a dinâmica das relações sociais provoca reações no Direito de modo que o intérprete precisa conjugar de forma aberta os seus comandos em consonância com as diretrizes humanistas e constitucionais. A compreensão do conteúdo jurídico deve perpassar o construto dogmático e kelseniano de visão do Direito porque tem por objetos a realidade social e a experiência jurídica do produto dessa realidade, isto é, o conteúdo jurídico deve se adequar (responder) ao existencialismo das necessidades da sociedade.

Nesse sentido, observa-se no plano teórico e prático uma tendência jurídica de problematização dos casos e aplicação concretista, a qual busca reinterpretar o Direito de modo que

$14 \quad$ Nesse sentido GONTIJO, 2011, passim. 
suas disposições normativas sejam flexibilizadas para se ajustar à realidade das relações privadas. O neoconstitucionalismo configurou passo importante para essa tarefa, mas as intensas inter-relações sociais provocam efeitos na doutrina e nos julgados e tendem à operacionalização e à aplicação de um Direito focado numa raiz mais humana e dialogada com a Carta Constitucional e com a perspectiva analítica pós-positivista.

Para a consecução desse efeito prático, faz-se necessário analisar o Direito dogmatizado, pois representado está por meio de um conjunto de normas compactadas e previamente elaboradas e postas (fechamento operacional), mas tendo em vista uma interpretação aberta capaz de direcionar na solução de possíveis conflitos que ocorrem no espaço social (adequação) $)^{15}$. O intérprete contemporâneo precisa refletir sobre o pós-positivismo a partir da comunicação que estabelece com outras ordens, precisando suas determinações e orientando para uma ordem finalista de caráter concretista ${ }^{16}$. Para o efeito prático, sustentado por princípios de socialidade, eticidade e operabilidade, o intérprete deve alinhavar seu pensamento jurídico perante os fatos sociais concretamente existentes na realidade fenomênica ${ }^{17}$, ou seja, diante da força probatória daquilo que é estabelecido e observável enquanto fato apurado e realizado no auditório universal (sociedade) ${ }^{18}$.

\footnotetext{
$15 \quad$ Nesse sentido, GONTIJO, 2011, p. 133.

16 Verifica-se, portanto, a necessidade do estabelecimento de dialética, na busca de conexões para estabelecimento de comunicação, buscando-se romper com o que Luhmann identifica como autopoiese, ou seja, a autoalimentação dos sistemas, que não levam em consideração quaisquer outras informações de outros meios. (1991).

17 Sobre o método fenomenológico de Martin Heidegger vide RIZZATTO NUNES, 2004, pp.60-61.

18 Trata-se do argumentum ad rem. De caráter universal, esse argumento é tido como vá-
} 
Essa ação deve encontrar-se imbuída de sentimento de retidão intertemporal em relação às suas consequências, pois o modo de ser (caráter) não deve se restringir ao imediatismo, pois o "dever-ser" não se encerra com a atuação no tempo presente. Toda a conduta humana possui desdobramentos futuros, dotados de continuidade de efeitos, não somente a médio, mas também em longo prazo. Constata-se, pois, responsabilidade no agir ético ${ }^{19}$.

Especificamente, no que tange à operabilidade do Direito, o intérprete deve nortear tal princípio sob a perspectiva do pensamento pós-positivista, a fim de assegurar valores de dignidade e de bem-estar da pessoa humana (humanização do conteúdo jurídico). O pensamento pós-positivista serve como parâmetro jurídico de aplicação da lei, e a lógica dessa postura interpretativa leva o hermeneuta a um constante processo de construção e reconstrução do Direito, e pode ensejar uma atuação jurídica mais justa e realista. E a humanização - fruto de espaço simbólico de luta e ação social - reside precisamente nesse modo de atuação que desencadeia um sentimento de valoração da aplicação de conteúdo jurídico humano e que vem sendo oportunizado a partir das crescentes respostas jurídicas (reflexões doutrinárias e jurisprudenciais) recobertas desse ativismo humanizante que passa a envolver o Direito.

A proposta deste artigo sustenta resposta antipositivista.

lido para todas as pessoas de forma indistinta, uma vez que sua observação e análise se processam em relação aos acontecimentos factuais e verdadeiros (FERRAZ JR., 1994, p. 340).

$19 \quad$ Nesse sentido, JONAS, 2006. 
Para tal, está arrimado basicamente sob dois prismas. O primeiro diz respeito à questão da conscientização jurídica sobre o tema. Deste decorrem os reflexos concretos que podem surtir no meio social, ou seja, a operabilidade de um Direito em harmonia com parâmetros de justiça, igualdade e solidariedade, portanto, humanizado e com maior potencialidade para se coadunar com a inevitável mutabilidade da dinâmica das relações sociais. Ainda nesse prisma, é preciso destacar a inserção da fundamentalidade da humanização e da abertura do Direito, no sentido de que a norma não pode ser vista enquanto fonte exclusiva do conteúdo jurídico, a ser aplicada de modo imperativo aos conflitos sociais mediante processo de subsunção, pois em verdade a pessoa humana corresponde à matéria-prima que deve nortear o conteúdo da lei e pautar a ação do hermeneuta em sua decisão. Assim é que a consciência do intérprete deve se ajustar a essa ideia de um Direito humanizado, sob pena de se recair numa estrutura jurídica petrificada e, por vezes, injusta e sem concretude social.

O segundo prisma envolve a questão dos parâmetros e limites de interpretação. É cediço que a humanização do Direito é relevante em virtude de sua importância fática, e este trabalho apoia essa ideia. Mas até mesmo o ato interpretativo deve ser eivado de carga valorativa que envolva proporcionalidade, sob pena de incidir em interpretação desarrazoada e de concretude equivocada e sem o devido teor operacional do qual ela deve se revestir.

Este artigo não pretende afastar ou extinguir a norma enquanto instrumento de realização do Direito. Em verdade, 
a proposta almeja reforçar os seus contornos normativos atribuindo-lhes respaldo humanístico, porém sem a necessidade de concebê-lo enquanto sistema, ou seja, como ordem perfeita, estruturada e delimitadora das condutas sociais. A temática sugerida gira em torno de um diálogo do Direito com outras metodologias e fontes, internas ou externas, ensejando aplicação do conhecimento jurídico que possa proporcionar correção normativa, isto é, aplicação da norma, mas valorada sob um juízo de adequabilidade à situação concreta.

Nesse passo interpretativo, também é importante destacar a Hermenêutica Jurídica ${ }^{20}$ para compor a abordagem humanística de percepção do Direito, pois abre espaço para a aplicação de outras metodologias e fontes, a exemplo da linguagem, a fim de se promover a relação dialógica aberta do pós-positivismo.

O olhar hermenêutico enseja a aproximação dos conteúdos dos diplomas legais, possibilita a flexibilização de princípios de direito e a ponderação de valores dentro de critérios de razoabilidade/proporcionalidade. Assim é que o ato interpretativo deve caminhar em consonância com a peculiar axiologia da ação humana comunicativa, sem perder de vista a norma, mas lhe atribuindo a devida correção normativa para que se adapte à realidade fenomênica.

Toda lei é obra humana e aplicada por homens;

20 A palavra Hermenêutica provém do grego Hermeneúein, interpretar, e deriva de Hermes, deus da mitologia grega, filho de Zeus e Maia, considerado o intérprete da vontade divina. Habitando a terra, era um deus próximo à Humanidade, o melhor amigo dos homens. (NADER, 2002, p. 261). 
portanto imperfeita na forma e no fundo, e dará duvidosos resultados práticos, se não verificarem, com esmero, o sentido e o alcance das suas prescrições. Incumbe ao intérprete aquela difícil tarefa. Procede à análise e também à reconstrução ou síntese. Examina o texto em si, o seu sentido, o significado de cada vocábulo. Faz depois obra de conjunto; compara-o com outros dispositivos da mesma lei, e com os de leis diversas, do país ou de fora. Inquire qual o fim da inclusão da regra no texto, e examina este tendo em vista o objetivo da lei toda e do Direito em geral. Determina por este processo o alcance da norma jurídica, e, assim, realiza, de modo completo, a obra moderna do hermeneuta (MAXIMILIANO, 2009, p. 8).

Busca-se, por meio das técnicas interpretativas ${ }^{21}$, concretização do que se almeja pela teoria pós-positivista. Verifica-se nas próprias palavras de Maximiliano a necessidade premente em não se buscar uma interpretação que considere o valor semântico das palavras, apenas. A busca por outras técnicas interpretativas fortalece a transição da teoria subjetiva para a teoria objetiva. Encontra-se nas técnicas lógica, sistemática e teleológica respaldo para tanto.

Sobre o elemento lógico, vale ressaltar a figura da lógica do razoável ${ }^{22}$, alimentada pela dinamicidade social, que clama

$21 \quad$ Nesse sentido, NADER, 2005.

22 Evidencia-se essa regulação por meio da lógica do razoável, que, nos dizeres de Lafer “(...) é razoável, no clima espiritual da modernidade, preocupar-se com o alcance e os limites epistemológicos dos procedimentos intelectuais que caracterizam a prática do Direito. É igualmente razoável procurar definir o Direito pela sua forma quando o processo de contínua mudança do Direito Positivo, por obra das necessidades de gestão da sociedade moderna, tomou impraticável definir o jurídico pelo seu conteúdo. É também razoável lidar com o descompasso 
por adequações no que tange à interpretação jurídica realizada pelos aplicadores do Direito. Princípios como razoabilidade e proporcionalidade buscaram inspiração em tal técnica ${ }^{23}$. Aquestão sistemática tem por finalidade demonstrar a imprescindível conexão entre áreas (ou subáreas), demonstrando a correlação necessária para a devida interpretação do caso concreto (ênfase da visão sistêmica para a devida sustentação do diálogo). Por fim, em relação ao elemento teleológico, busca-se a finalidade a ser atingida pela devida aplicação da justiça, por meio da dialética entre direito pressuposto e direito posto, fundamentada em uma ética alicerçada sob o princípio da responsabilidade.

Os elementos acima mencionados, portanto, auxiliam na relação (e por que não dizer na percepção) entre o jurídico e o social, pela aproximação entre fato e norma, buscando, por meio da equidade, efetividade da devida harmonização necessária para tanto.

\section{CONSIDERAÇÕES FINAIS}

FalaremEstadoéremeteraosseus elementos constitutivos: soberania, território e povo. Este último corresponde à "vida estatal" porque é o componente que dá cadência e atribui dinâmica às relações que fomentam a sobrevivência social, política e econômica de um Estado. Este, ao seu turno, passa a

entre a norma formal e a realidade social quando este descompasso se generaliza. Finalmente, é razoável discutir criticamente os valores de Justiça contidos no Direito Positivo diante da crise generalizada de legitimidade do poder que positiva a legalidade". (1988, p. 18).

$23 \quad$ NADER, 2005, p. 278. 
sentir reflexos em sua órbita (legislação, jurídico-interpretativa e democrática) quando fatores ontológicos, ou mesmo deontológicos, alteram o ritmo grupal de seu povo.

Essa comunicação entre Estado e povo enseja mudanças de paradigmas à atual estrutura democrática, principalmente sob o enfoque jurídico. No plano do Direito, reconstruir paradigmas está atrelado à ideia de se atribuir nova roupagem ao conhecimento jurídico e ao pensamento jusfilosófico para que estes possam culminar respostas às novas realidades e necessidades da sociedade, e compete não apenas ao Estadolegislador, mas também ao Estado-juiz o poder para fomentar tais transformações em consonância com a ordem democrática, uma vez que democracia é instituto (regime de governo) que se constrói em abstrato para se projetar in concreto, e a sua edificação é embalada dentro de um cenário complexo de atuação que comporta sujeitos detentores de direitos e deveres. Nessa senda, conferir ao Direito maior efetividade e consonância social harmoniza-se com a contemporânea ideia de democracia (reconstrução de paradigmas) que deve ser realizável dentro de um Estado formado por um ambiente multicultural e de diversidades que se expressam sob diferentes aspectos sociais.

Este artigo defende o pós-positivismo como argumento opositor e tendente a romper com o modelo positivista de aplicação do Direito. Assim, o Direito semeado sob essa perspectiva apoia uma maior efetividade de aplicação do conteúdo jurídico às relações sociais, bem como a elaboração teórica de contribuição jurídica que possa sustentar a reflexão 
sobre sua humanização. Nesse passo, o aspecto metodológico - que neste artigo apresenta-se ser aberto - ganha dimensão à medida que ensejar a operacionalização social que se espera do Direito.

Assim, suscita-se discussão que possa trazer contribuições a partir de uma releitura aberta do Direito em sintonia com a proposta pós-positivista atinente à Teoria do Direito, objetivando acentuar o humanismo no que toca à aplicação e adequabilidade às relações sociais.

\section{REFERÊNCIAS}

ARENDT, Hannah. A condição humana. 9. ed. Trad. Roberto Raposo. Rio de Janeiro: Forense Universitária, 1999.

AVRITZER, Leonardo. Teoria democrática e deliberação pública. Disponível em>http://www.scielo.br/pdf/ln/n50/ a03n50.pdf $<$. Acesso em 21 de novembro de 2012.

BARROSO, Luís Roberto. Curso de direito constitucional contemporâneo. 2. ed. São Paulo: Saraiva, 2010.

BRASIL. Código civil brasileiro. ANGHER, Anne Joyce (org.). In: Vade mecum: acadêmico de direito. 11. ed. São Paulo: Rideel, 2010. 
. Constituição da República Federativa do Brasil de 1988. 45. ed. São Paulo: Saraiva, 2011.

BULOS, Uadi Lammêgo. Curso de direito constitucional. 5. ed. São Paulo: Saraiva, 2010.

FERRAZ JR., Tercio Sampaio. Introdução ao estudo do direito: técnica, decisão, dominação. 2. ed. São Paulo: Atlas, 1994.

FIUZA, César. Perigos de uma hermenêutica civilconstitucional. Disponível em <http://www.pucminas.br/ documentos/editora_revista_direito_numero_22.pdf $>$. Acesso em 20 de novembro 2012.

GALUPPO, Marcelo Campos. Metodologia da pesquisa. Belo Horizonte: PUC Minas Virtual, 2007.

O direito civil no contexto da superação do positivismo jurídico: a questão do sistema. Disponível em $<$ http://books.google.com.br/books?isbn=8573086025>. Acesso em 13 de maio de 2013.

. A epistemologia jurídica entre o positivismo e o póspositivismo. Disponível em $<$ http://webdav.sistemas.pucminas. br:8080/.../338466_A\%20epistemologia\%20j>. Acesso em 20 de abril de 2013. 
GONTIJO, Lucas de Alvarenga. Filosofia do direito: metodologia jurídica, teoria da argumentação e guinada linguístico-pragmática. Belo Horizonte: Arraes Editores, 2011.

GRAU, Eros Roberto. O direito posto e o direito pressuposto. São Paulo: Malheiros, 1996.

GUERRA FILHO, Willis Santiago (coord.). Dos direitos humanos aos direitos fundamentais. Porto Alegre: Livraria do Advogado, 1997.

. Teoria da ciência jurídica. 2. ed. São Paulo: Saraiva, 2009.

HAARCHER, Guy. A filosofia dos direitos do homem. Lisboa: Astória, 1993.

HABERMAS, Jürgen. Técnica e ciência como ideologia. Lisboa: Edições 70, 1987.

HUNT, Lynn. A invenção dos direitos humanos: uma história. São Paulo: Companhia das letras, 2009.

JONAS, Hans. O princípio responsabilidade: ensaio de uma ética para a civilização tecnológica. Tradução do original alemão Marijane Lisboa, Luiz Barros Montez. Rio de Janeiro: Contraponto: PUC Rio, 2006. 
KELSEN, Hans. Teoria pura do direito. São Paulo: Martins Fontes, 1999.

LAFER, Celso. A reconstrução dos direitos humanos: um diálogo com o pensamento de Hannah Arendt. São Paulo: Companhia das Letras, 1988

LUHMANN, Niklas. Sociología del riesgo. Tradução: Silvia Pappe, Brunhilde Erker, Luis Felipe Segura, Javier Torres Nafarrate. Guadalajara: Universidade Iberoamericana Universidade de Guadalajara, 1991.

MARCONI, Mariana de Andrade; LAKATOS, Eva Maria. Metodologia científica. 3. ed. São Paulo: Atlas, 2000.

MAXIMILIANO. Carlos. Hermenêutica e aplicação do direito. 19. ed. Rio de Janeiro: Forense, 2009.

MODESTO, Paloma Santana. A eficácia dos direitos humanos fundamentais nas relações jurídicas privadas. Revista do Curso de Direito das Faculdades Jorge Amado. Salvador: Faculdades Jorge Amado, $n^{\circ}$ 1, 2002.

NADER, Paulo. Introdução ao estudo do direito. 25. ed. Rio de Janeiro: Forense, 2005.

PIOVESAN, Flávia. Direitos humanos e o direito 
constitucional internacional. 12. ed. São Paulo: Saraiva, 2011.

REALE, Miguel. Lições preliminares de direito. 27. ed. São Paulo: Saraiva, 2009.

REZEK, Francisco. Direito internacional público. 13. ed. São Paulo: Saraiva, 2011.

RIZZATTO NUNES, Luiz Antonio. O princípio constitucional da dignidade da pessoa humana. São Paulo: Saraiva, 2002.

. Manual de filosofia do direito. São Paulo: Saraiva, 2004.

SANTOS, Boaventura de Sousa. A crítica da razão indolente. 5. ed. São Paulo: Cortez Editora, 2005.

Recebido em: 24/06/2014

Aprovado em: 22/07/2014 